\title{
Ideal Failure Curve of Rolling Contact Bearings
}

\author{
Y. Meged \\ The Technion, Faculty of Mechanical Engineering, Israel Institute of Technology, Haifa, Israel \\ Email: ygoodi@013.net.il
}

How to cite this paper: Meged, Y. (2020) Ideal Failure Curve of Rolling Contact Bearings. Advances in Materials Physics and Chemistry, 10, 297-303. https://doi.org/10.4236/ampc.2020.1011023

Received: October 24, 2020

Accepted: November 27, 2020

Published: November 30, 2020

Copyright $\odot 2020$ by author(s) and Scientific Research Publishing Inc. This work is licensed under the Creative Commons Attribution International License (CC BY 4.0).

http://creativecommons.org/licenses/by/4.0/

\begin{abstract}
The prevailing cumulative failure curves of Rolling Contact Bearings (RCB) have two main drawbacks: they begin at the origin and have a large dispersion. The purpose of this study is to develop an ideal failure curve and overcome the present drawbacks. The ideal failure curve of RC bearings is obtained by applying a water-free lubricant to the tested bearings. This eliminates the cavitation erosion from the Bimodal failure mechanism and the synergistic effect with the mechanical failure mode. This new concept considers the fatigue process involved in the failure mechanism and suggests decreasing the dispersion of bearing life.
\end{abstract}

\section{Keywords}

Bimodal Failure Mechanism, Hertzian Failure Mode, Cavitation Erosion, Rolling Contact Bearings, Synergism, SWater Absorption by Lubricants, Water Content of Lubricants

\section{Introduction}

In the book "Fundamentals of Mechanical Design" [1] R. H. Phelan presents a cumulative failure curve (Figure 1) for rolling contact, RC, bearings. This curve was compiled by SKF, the Swedish Ball Bearing Company. It is similar to the failure curves for all types of RC bearings. It further reveals a wide dispersion range of bearing life, reaching a span of 20:1.

High local and frequent loadings are typical of both Hertzian and cavitation loads that prevail in RC bearings. These types of loads cause fatigue stresses, requiring some time to develop damage. Thus it is impossible to obtain bearing failure right from the beginning of bearing operation, as shown in Figure 1.

Both these shortcomings cast heavy doubt on the validity of Figure 1 as a representative of RC bearing failure. These observations call for a new type of failure curve for RC bearings. 


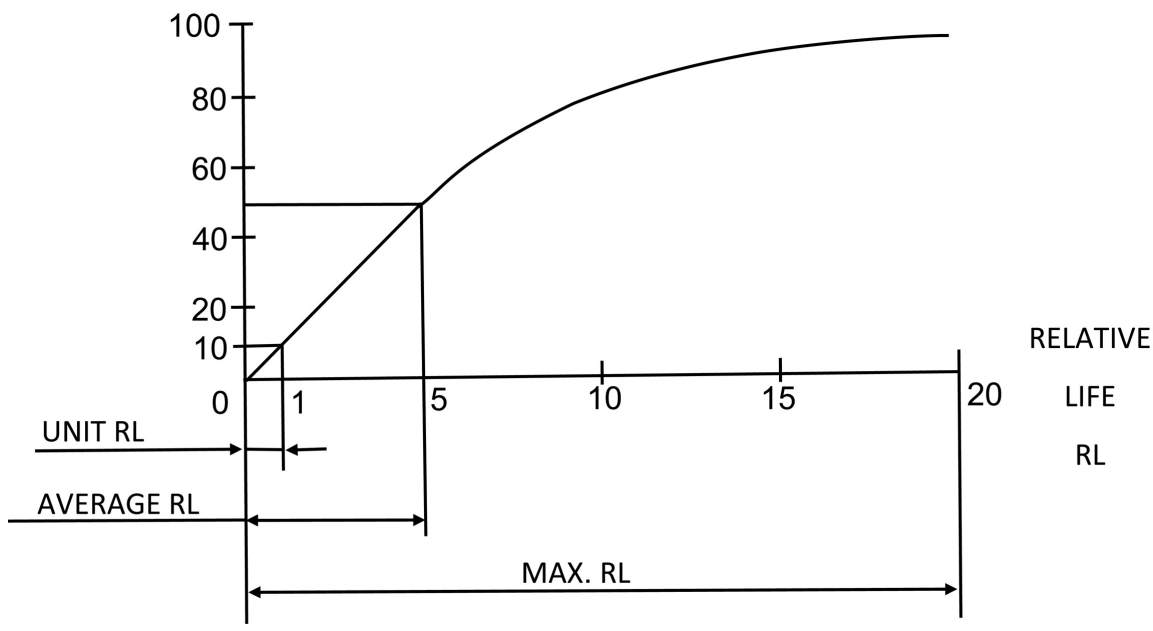

Figure 1. Cumulative failure curve for rolling contact bearings as compiled by SKF (1).

\section{Discussion}

\subsection{Water Absorption by Lubricating Oils}

Cantley [2] studied the exposure effects of lubricating fluids to the relative humidity of the atmosphere at the levels of $20 \%, 60 \%$ and $100 \%$. He observed that "the addition of additives to the base fluid always increases the capacity for moisture absorption". In Figure 2 Cantley presents test results of four synthetic lubricants. One of these fluids, number 12 , shows low water absorption capability, while the three other fluids show considerable moisture absorbing capability, from approximately $400 \mathrm{ppm}$ to $36,000 \mathrm{ppm}$.

Cantley concluded that "The water absorbing capability of a lubricating oil could represent an important factor in bearing life evaluations." He further states: "The significant effect of low concentrations of water on bearing life. The wide variation in water absorbing properties of lubricants makes it reasonable to conclude that the inherent water content of an oil could significantly affect fatigue life".

The results in Figure 2 for synthetic lubricants are typical for mineral oils and Extreme Pressure lubricants, too. However, each type of lubricant covers a different range of water absorption. To illustrate the dispersion of results let us look at the water content of the three types of lubricants at the relative humidity of $20 \%$ and the temperature of $30 \mathrm{C}$, see Figure 3 :

1) Mineral oils: 32 - 207 ppm.

2) Extreme Pressure fluids: 78 - 220 ppm.

3) Synthetic fluids: 48 - 890 ppm.

It should be noted that all these values were beyond $25 \mathrm{ppm}$, at which full scale RC bearings were tested and found causing detrimental effects on their service life [2].

\subsection{Dispersion of RC Bearing Life}

The Bimodal failure mechanism of RC bearings is comprised of the mechanical 


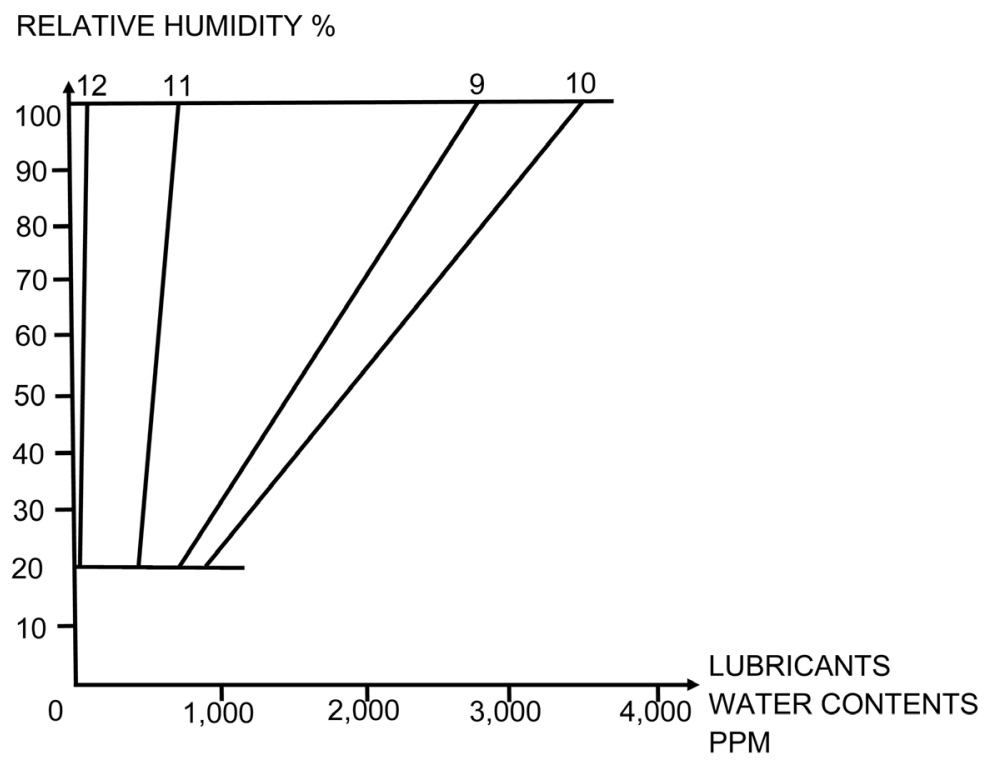

Figure 2. Water absorption characteristics of synthetic lubricants as function of relative humidity at $30 \mathrm{C}$.

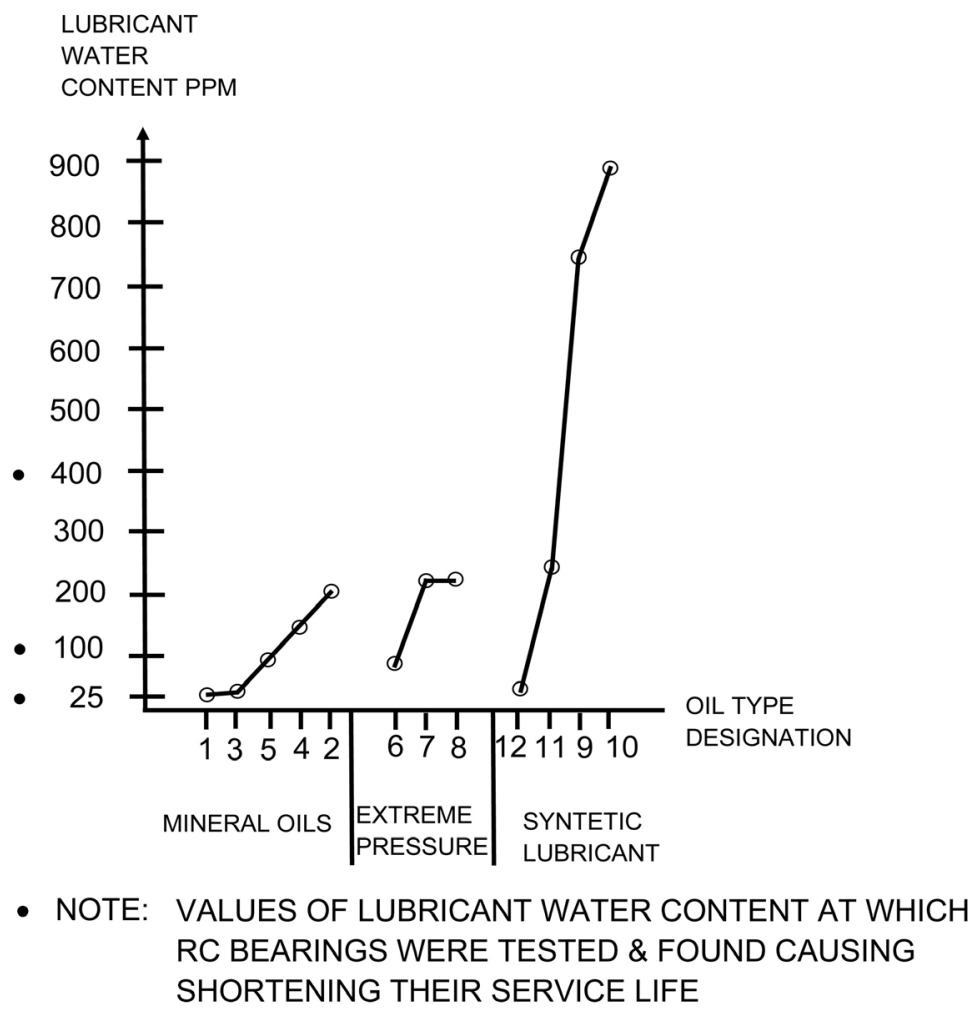

Figure 3. Three types of lubricants and their water contents at the relative humidity of $20 \%$ at $30 \mathrm{C}$.

and hydraulic modes [3]. The mechanical mode, based on the Hertzian local contact stresses, is well treated both theoretically and practically by the life testing procedures. On the other hand the hydraulic mode is disregarded. As a result nearly no attention is paid to the lubricant, its water content and its absorption 
capability.

It is well known that water in the lubricant has a detrimental effect on RC bearing life [2]. This effect is caused by the cavitation of the water under the oscillating contact pressure, formation and collapse of vapor filled cavities. This process results in high local pressures on the bearing surfaces. Both these modes act simultaneously. The mixed effect of both modes, with one of them uncontrolled, is the direct cause of the large dispersion of RC bearing life, under testing and actual service conditions. Under the prevailing conditions the hydraulic failure mode randomizes and shortens the service life of RC bearings. It furthermore has a synergistic effect with the mechanical failure mode, by enhancing the pitting of the contact area.

\section{Ideal Failure Curve}

\subsection{Concept}

The drawbacks of the curve in Figure 1 are the data at the origin and the large dispersion of bearing life. The following section presents an idealized curve, overcoming these drawbacks. The concept behind the new curve is to minimize the effects of the hydraulic failure mode. In order to achieve this goal the lubricant must be water-free thus avoiding cavitation, the erosion and the synergistic effect, too.

\subsection{The Ideal Curve (Figure 4)}

1) Grid: The grid for this curve is identical to that of Figure 1, namely:

- The horizontal axis is the relative bearing life RL.

- The vertical axis is the percentage bearing failure F\%.

2) Curve structure: The schematic illustrative curve is bi-lineal, consisting of two straight lines:

- Line OA: This line, conforming with the $\mathrm{X}$ axis, is the no-failure zone. The fatigue process is developing, but no failure has yet occurred.

- Line AB: This line represents the actual bearing failures developing by the mechanical oscillating loadings.

3) Dispersion: The bearing life dispersion is measured between the $X$-values of points A and B. In Figure 4 the dispersion is cut by half compared to that shown in Figure 1, reaching the value of 1:10. As this curve is illustrative it overcomes the drawbacks of the curve in Figure 1 and shows the potential of applying water-free lubricants.

\section{Conclusions and Recommendations}

According to the bimodal failure mechanism concept of RC bearings, the failure modes are mechanical and hydraulic. The lubricant absorbs water from the atmosphere and cavitates under the fluctuating high local loads, thereby causing formation of vapor filled cavities. Upon reaching a high pressure zone, the cavities collapse. This process is exothermal, accompanied by a temperature rise of 


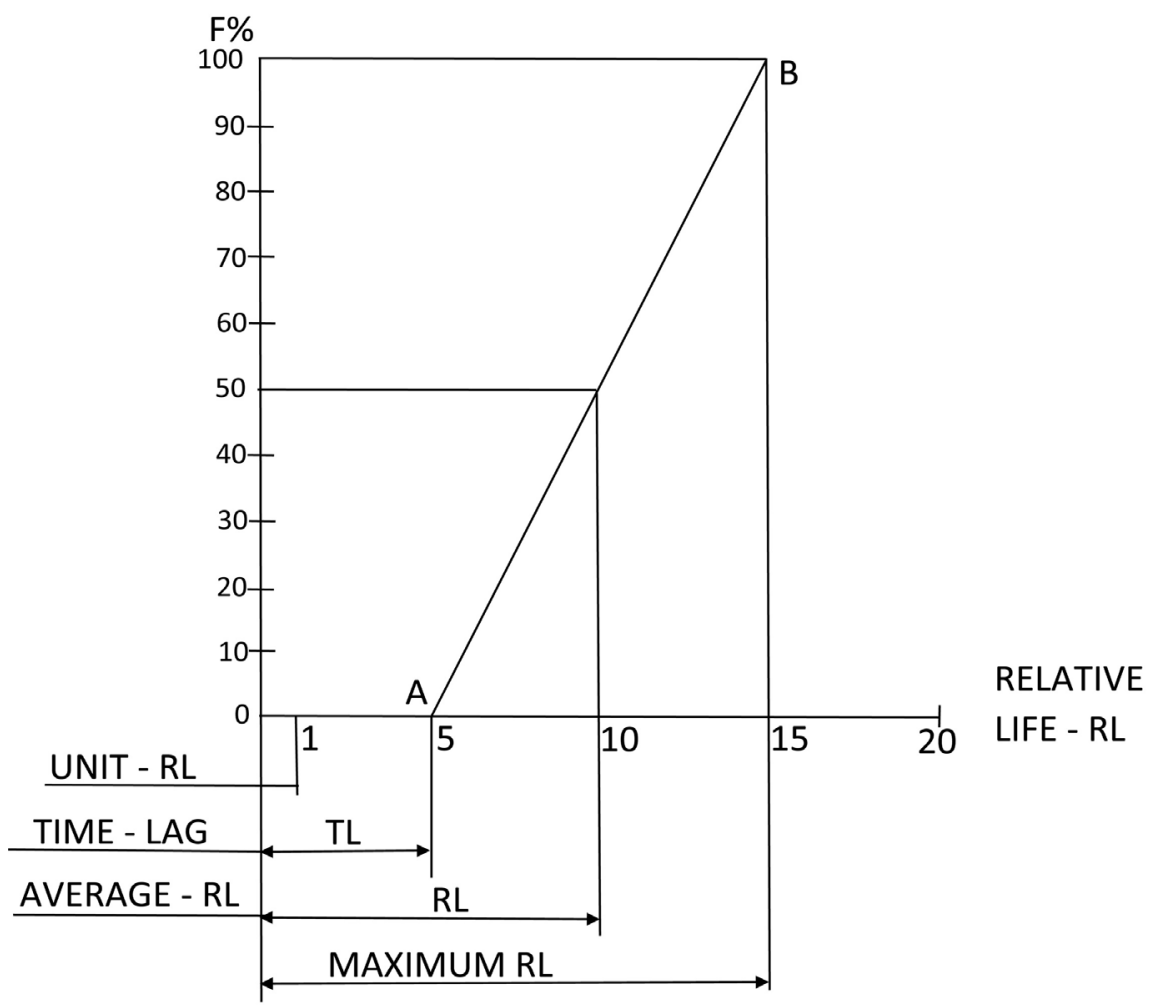

Figure 4. Idealized failure curve of RC bearings.

2000C and a pressure peak of 30,000 at. These conditions cause high local loadings and pitting on the bearing's surface. This damage process overlaps that of the mechanical loading, thereby causing a synergistic effect. This analysis explains why water in the lubricant, with a content as low as $25 \mathrm{ppm}$, has a detrimental effect on RC bearings by shortening their service life considerably [2].

\subsection{Lubricants}

The main conclusion of this study is the importance of lubricating RC bearings with water-free lubricants. This recommendation can be achieved by dehydration of the lubricant. The best way is by using the Compact Membrane System [4]. In case this method is not applicable, it is recommended to lubricate the bearings with the best available liquid such as shown in Appendix A:

1) SAE 5 mineral oil (NO. 1).

2) SAE 20 mineral oil with rust and oxidation inhibitor (NO. 3).

3) Synthetic oil-Hydro carbon fluid (NO. 12).

It is recommended to develop new lubricants, with minimum additives, and minimal water absorption.

It is recommended to formulate new standards and specifications for the new lubricants and their testing procedures.

\subsection{Ideal Failure Curve}

This study led to the formation of a new cumulative failure curve, Figure 4, 
based on the minimization of lubricant cavitation. As a result both drawbacks of the prevailing curve (Figure 1) are eliminated and the RC bearing service life is improved.

\section{Acknowledgements}

Many thanks to Dr. Janusz Steller from the Institute of Fluid-Flow Machinery, at the Polish Academy of Science. He is the coordinator of the International Cavitation Erosion Test, ICET. Thanks for furnishing me with the abundant report of the project. The report is the result of tests performed by 15 laboratories from 11 countries worldwide.

\section{Conflicts of Interest}

The author declares no conflicts of interest regarding the publication of this paper.

\section{References}

[1] Phelan, R.M. (1962) Fundamentals of Mechanical Design. McGraw Hill, Library of Congress Card Number 62-14221, 436.

[2] Cantley, R.E. (1976) The Effect of Water in Lubricating Oils on Bearing Fatigue Life. ASLE Transactions, 20, 244-248. https://doi.org/10.1080/05698197708982838

[3] Meged, Y. (2020) Bimodal Failure Mechanism of Rolling Contact Bearings. Advances in Materials, Physics and Chemistry, 10, 230-238. https://doi.org/10.4236/ampc.2020.1010017

[4] Williamson, A. (2020) Machinery Lubrication Engineering.

\section{Nomenclature}

$\mathrm{CE}=$ cavitation erosion

$\mathrm{CMS}=$ compact membrane system

$\mathrm{EP}=$ extreme pressure

$\mathrm{F}=$ bearing failure percentage $\%$

$\mathrm{RCB}=$ rolling contact bearings

$\mathrm{RL}=$ relative life

$\mathrm{TL}=$ time lag, no-failure zone 


\section{Appendix A: Lubricants Tested for Water Absorption (2)}

Test conditions: Temperature $-30^{\circ} \mathrm{C}$

Relative humidity - 20\%, 60\%, 100\%

\begin{tabular}{lll}
\hline Type & Number & Sample Identification \\
Mineral Oil & 1 & SAE 5 Mineral Oil \\
& 2 & SAE 5 + EP additives \\
& 4 & SAE 20 Mineral Oil + Rust \& Oxidation inhibitor \\
& 5 & SAE 20 + Phosphorous additive \\
& & SAE 20 + EP additives \\
\hline EP & 6 & Commercial EP Gear Oil \\
& 7 & Commercial EP Gear Oil \\
& 9 & Commercial EP Gear Oil \\
Synthetic & 10 & Synthetic Fluid (Diester) \\
& 11 & Synthetic Fluid ( Neopentyl Polyol Ester) \\
& 12 & Synthetic Hydrocarbon Fluid
\end{tabular}

